\title{
BMJ Open Patient satisfaction with in-centre haemodialysis care: an international survey
}

\author{
Suetonia C Palmer, ${ }^{1}$ Giorgia de Berardis, ${ }^{2}$ Jonathan C Craig, ${ }^{3}$ Allison Tong, ${ }^{3}$ \\ Marcello Tonelli, ${ }^{4}$ Fabio Pellegrini, ${ }^{2,5}$ Marinella Ruospo, ${ }^{6}$ Jörgen Hegbrant, ${ }^{6}$ \\ Charlotta Wollheim, ${ }^{6}$ Eduardo Celia, ${ }^{6}$ Ruben Gelfman, ${ }^{6}$ Juan Nin Ferrari, ${ }^{6}$ \\ Marietta Törok, ${ }^{6}$ Marco Murgo, ${ }^{6}$ Miguel Leal, ${ }^{6}$ Anna Bednarek-Skublewska, ${ }^{6}$ \\ Jan Dulawa, ${ }^{6}$ Giovanni F M Strippoli ${ }^{2,3,6,7,8}$
}

To cite: Palmer SC, de Berardis G, Craig JC, et al. Patient satisfaction with in-centre haemodialysis care: an international survey. BMJ Open 2014;4:e005020. doi:10.1136/bmjopen-2014005020

- Prepublication history and additional material is available. To view please visit the journal (http://dx.doi.org/ 10.1136/bmjopen-2014005020).

This paper has previously been presented in abstract form at the American Society of Nephrology Kidney Week 2013, Atlanta, as a poster communication on Friday, 8 November 2013

Received 7 February 2014 Revised 28 April 2014 Accepted 30 April 2014

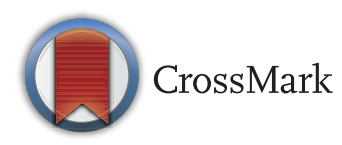

For numbered affiliations see end of article.

Correspondence to Professor Giovanni F M Strippoli;

gfmstrippoli@gmail.com

\section{ABSTRACT}

Objectives: To evaluate patient experiences of specific aspects of haemodialysis care across several countries. Design: Cross-sectional survey using the Choices for Healthy Outcomes in Caring for End-Stage Renal Disease (CHOICE) questionnaire.

Setting: Haemodialysis clinics within a single provider in Europe and South America.

Participants: 2748 adults treated in haemodialysis. Primary and secondary outcomes: The primary outcome was patient satisfaction with overall care. Secondary outcomes included patient experiences of individual aspects of dialysis care.

Results: $2145(78.1 \%)$ adults responded to the questionnaire. Fewer than half $(46.5 \%(95 \% \mathrm{Cl} 44.5 \%$ to $48.6 \%)$ ) rated their overall care as excellent. Global perceptions of care were uninfluenced by most respondent characteristics except age and depressive symptoms; older respondents were less critical of their care (adjusted OR for excellent rating 1.44 (1.01 to 2.04)) and those with depressive symptoms were less satisfied (0.56 (0.44 to 0.71)). Aspects of care that respondents most frequently ranked as excellent were staff attention to dialysis vascular access $(54 \%)(52 \%$ to $56 \%))$; caring of nurses (53\% (51\% to $55 \%)$ ); staff responsiveness to pain or discomfort $(51 \%$ ( $49 \%$ to $53 \%)$ ); caring, helpfulness and sensitivity of dialysis staff ( $50 \%(48 \%$ to $52 \%))$; and ease of reaching dialysis staff by telephone ( $48 \%$ (46\% to $50 \%)$ ). The aspects of care least frequently ranked as excellent were information provided when choosing a dialysis modality $(23 \%(21 \%$ to $25 \%))$, ease of seeing a social worker (28\% $(24 \%$ to $32 \%))$, information provided about dialysis $(34 \%(32 \%$ to $36 \%))$, accuracy of information from nephrologist (eg, about prognosis or likelihood of a kidney transplant; $37 \%(35 \%$ to $39 \%)$ ) and accuracy of nephrologists' instructions (39\% (36\% to $41 \%)$ ).

Conclusions: Haemodialysis patients are least satisfied with the complex aspects of care. Patients' expectations for accurate information, prognosis, the likelihood of kidney transplantation and their options when choosing dialysis treatment need to be considered when planning healthcare research and practices.

\section{Strengths and limitations of this study}

- The study is based on a large multinational survey of patients with chronic kidney failure needing treatment with long-term dialysis. There were no specific exclusions other than refusal or inability to complete the survey questions.

- This study adds knowledge across a large cohort of the specific aspects of dialysis care that fewer patients find satisfactory.

- The limitations were the lack of data about the health service characteristics that might have contributed to patient experiences as well as linkages to patient relevant outcomes.

\section{INTRODUCTION}

Patients treated with haemodialysis experience mortality rates approaching 15-20\% each year $^{1}$ and have profoundly impaired quality of life, ${ }^{2}{ }^{3}$ contributed to by severe symptoms of fatigue, low appetite, pain, sleep disorders, anxiety, nausea and restless legs. ${ }^{4}$ While interventions in haemodialysis trials and healthcare regulations have largely focused on biomarker endpoints and quantitative outcomes (mortality and cardiovascular events) to evaluate care, dialysis patients value normalisation of their lives, economic efficiency in healthcare and how their personal preferences are met, including reducing dietary and travel restrictions. ${ }^{5}{ }^{6}$ This mismatch in patient, provider and research priorities has resulted in clinical research and practice that have not improved patientcentred outcomes for dialysis patients ${ }^{7-11}$ and consumed considerable resources. ${ }^{12}$

Given that patients treated with in-centre haemodialysis attend dialysis care at least three times per week for several hours each time, their experiences of dialysis care are likely to have an important impact on living 
with chronic illness. ${ }^{3}{ }^{13}$ In contrast, health funders have traditionally used only clinical performance indicators such as anaemia, blood pressure, nutrition, dialysis vascular access and adequacy of solute removal to evaluate and allocate reimbursement for dialysis provision. ${ }^{14-17}$ While improving patient satisfaction with dialysis treatment has the potential to increase quality of life and improve patient-level outcomes, data to inform this objective are scarce. ${ }^{18}{ }^{19}$ Studies indicate that healthcare delivery in the later stages of chronic kidney disease such as predialysis nephrology care, multidisciplinary management, psychoeducation interventions and prognosis communication may improve quantitative health outcomes in the dialysis setting, but there is little information on the effects of these strategies on outcomes relevant to patients, that include symptoms, function and quality of life. ${ }^{20-24}$ In addition, evaluations of patient experiences of haemodialysis care are available and can shape our knowledge about what patients value, but in existing studies smaller population sizes within single countries limit the power to adjust for case mix, ${ }^{19}$ and perceptions of care are limited to global scores which may restrict our understanding of the contributions of specific, and potentially modifiable, aspects of care on overall patient experience. ${ }^{18}$

Greater understanding of how patients experience all facets of long-term dialysis is needed to inform the design of large-scale trials which evaluate targeted healthcare strategies to improve the lives of dialysis patients in ways they value. Accordingly, we aimed, for the first time, to describe patient satisfaction with haemodialysis care in a large multinational cohort to assess patients' experiences of haemodialysis care while accounting for clinical and demographic characteristics.

\section{METHODS}

\section{Participants}

We used data from Diaverum, a network that provides renal care including long-term in-centre haemodialysis treatment for more than 20000 patients in Europe and South America and surveys patients at least annually about their satisfaction with care. We conducted a crosssectional analysis of routinely gathered survey data collected in 2008. We selected a convenience sample of $15 \%$ of patients in the network from clinics that were willing to contribute. Data were included for selected patients who were aged 18 years or older and treated with haemodialysis between January and June 2008 in centres located in Europe (Hungary, Italy, Poland and Portugal) and South America (Argentina). All clinical centres were managed during the study period according to the same standards of care. Of the 2748 patients selected (Argentina, $\mathrm{n}=670$; Hungary, $\mathrm{n}=683$; Italy, $\mathrm{n}=880$; Poland, $\mathrm{n}=477 ;$ Portugal, $\mathrm{n}=38), 2145(78.1 \%)$ responded and $1846(67.2 \%)$ provided complete responses to all questions. The study was conducted according to the requirements of the Declaration of
Helsinki. The mean age and gender composition of our cohort is similar to prevalent patients treated with kidney replacement therapy in Europe. ${ }^{25}$

\section{Key measures}

We collected data from patient responses to the Choices for Healthy Outcomes in Caring for End-Stage Renal Disease (CHOICE) questionnaire, which evaluates satisfaction with dialysis treatment (see the online Appendix for the full survey). ${ }^{26}$ The CHOICE questionnaire was originally developed by Rubin and colleagues using a focus group of long-term in-centre haemodialysis and home-based peritoneal dialysis patients to identify aspects of dialysis care most important to them. The items identified were then ranked by a larger number of long-term dialysis patients to identify the top 25 items they considered extremely important. The questionnaire asks 20 questions about patients' experiences relating to these different aspects of dialysis care on a 5-point Likert scale (poor, fair, good, very good, excellent). In addition, three questions ask patients to rate the overall quality of their care (poor, fair, good, very good, excellent or not applicable), how much about their care could be better (many things, a few things, one or two things, and nothing could be better at all) and whether they would recommend their care service to others who may need dialysis care (definitely not, probably not, not sure, probably yes and definitely yes; see online supplementary online Table 1). In addition, we summarised measures of key performance indicators for dialysis within each country (see online supplementary online Table 2) for the two quarters in which satisfaction data were collected and reported these as overall performance scores for each participating country.

In the present analysis, the question 'How easy is it to meet the social worker when you want to?' was only included in the annual survey in Hungary and the two global questions about care 'Thinking about your dialysis care overall, how much could be better?' and 'Would you recommend your dialysis centre to a friend or relative who needs dialysis?' were omitted in the annual survey of Italian patients.

Surveys were provided to patients by dialysis clinical staff during routine dialysis care. Patients self-completed the questionnaires anonymously during a dialysis session and data were de-identified. We then linked survey data to concurrent demographic, clinical and laboratory information in a clinical database using a unique patient identifier; additional data were provided where necessary by the treating physician on a standardised case report form. We used questionnaires in the patients' native language after translation and linguistic validation by the MAPI Institute (http://www.mapi-institute.com).

\section{Analysis}

We considered a response to the survey as complete when interpretable answers were provided for all survey questions and partially complete when one or more 
answers were missing. We used $\chi^{2}$ tests and Mann-Whitney $\mathrm{U}$ tests to compare the characteristics of patients who responded to the survey with those who did not. The primary outcome of interest was the proportion of respondents who evaluated their overall care as 'excellent'. We also estimated the proportion of respondents who evaluated each separate dimension of care as 'excellent'. To account for the multilevel nature of the data (patients clustered within countries) and to control simultaneously for the possible confounding effects of the different variables, we used multivariate multilevel logistic regression models. ${ }^{27}{ }^{28}$ We constructed clustering and case mix adjusted models that controlled for the following potential confounding variables: age, gender, education level, occupational status, marital status, distance to travel to the dialysis centre, kidney transplant waiting list status, comorbid conditions (diabetes mellitus, hypertension, cardiovascular event), depression score, cause of end-stage kidney disease, duration of dialysis per session, dialysis dose, adequacy of dialysis and serum values of haemoglobin and phosphorus. We performed multilevel logistic regression using the SAS language macro routine Proc GLIMMIX (SAS Institute Inc, Cary, North Carolina, USA; Release V.9.1, 2002-2003; http://www.sas.com).

\section{RESULTS}

Characteristics of patients in the network and respondents to questionnaire

Respondents were younger and lived closer to their dialysis centre than non-respondents (table 1). Questionnaire response rates differed by country; patients in Portugal were most likely to respond to the survey $(97.4 \%)$, with decreasing response rates in Argentina (81.9\%), Hungary $(81.4 \%)$, Poland $(74.4 \%)$ and Italy $(73.6 \%)$. Overall, respondents were $61.0 \pm 15.5$ years, most were men $(55.5 \%), 40.2 \%$ had $6-8$ years of school education and about half had depressive symptoms according to the Center for Epidemiological Studies-Depression (CES-D) Scale (score of 18 or above). Two-thirds of respondents were married $(60.8 \%)$, most were unemployed $(68.8 \%)$ and a minority had previously received a kidney transplant $(6.9 \%)$

\section{Survey responses}

Fewer than half of respondents rated their overall care as excellent $(1057 / 2271 ; 46.5 \% \quad(95 \%$ CI $44.5 \%$ to $48.6 \%)$ ) and about three-quarters rated their care as excellent or very good $(1783 / 2271 ; 78.5 \%$ (CI $76.8 \%$ to $80.2 \%)$; figure 1$)$. The proportion rating their overall care as excellent was lowest in Poland (13.7\%), with an increasing proportion in Argentina (30.3\%), Italy $(61.2 \%)$, Hungary (63.5\%) and Portugal (83.8\%;see online supplementary online Table 1$)$.

Table 2 shows the association between respondent characteristics and the proportion rating haemodialysis care as excellent. In analyses clustered by country and controlled for demographic and clinical variables, older respondents were more likely to consider care excellent (adjusted OR (AOR) for those 70 years or older, 1.44 (CI 1.01 to 2.04) compared with those aged 18-49 years) and those with depressive symptoms were less likely to consider that care met excellent standards (AOR 0.56 (CI 0.44 to 0.71$)$ ) compared to those without depressive symptoms. Gender, education, marital status, comorbidity (including diabetes and cardiovascular disease) and the time spent on dialysis each week were not associated with perspectives of overall care.

Figure 1 shows the proportion of respondents who considered that nothing about their care could be better, and online supplementary online Table 3 provides responses according to clinical, demographic and treatment-based characteristics. Overall, about one-third of respondents considered that nothing about their care could be better (486/1477; 32.9\% (CI $30.6 \%$ to $35.3 \%)$ ). Respondents aged 70 years or older (AOR 2.20 (CI 1.47 to 3.31)) and those living further away from their dialysis centre (AOR 1.39 (CI 1.04 to 1.85)) were more likely to consider that no aspect of their care required improvement. In the four countries in which this question was asked (Argentina, Hungary, Poland and Portugal), compared with Argentina, patients in Hungary (AOR 1.37 (CI 1.06 to 1.77)) and Poland (AOR 1.82 (CI 1.37 to 2.42)) were more likely to consider than nothing about their care needed to be changed.

In the four countries in which the question 'would you recommend your dialysis centre to a friend or relative who needed dialysis?' was asked, 1022 of 1587 respondents $(64.4 \%$ (CI $62.0 \%$ to $66.7 \%)$ ) would definitely recommend their dialysis centre. Older respondents (AOR 1.84 (CI 1.24 to 2.74)) and those living further from their dialysis centre (AOR 1.37 (CI 1.03 to 1.83)) were more likely to recommend their dialysis centre to others for care, whereas those with depressive symptoms were less likely to recommend their care to others (AOR 0.67 (CI 0.51 to 0.87 ); see online supplementary eTable 4). Compared with Argentina, strong recommendations would more likely be made by respondents in Hungary (AOR 2.38 (CI 1.84 to 3.07)) and Portugal (AOR 28.2 (CI 3.84 to 207.39)).

The five items that respondents rated most frequently as excellent were 'attention of staff to cleanliness of the dialysis vascular access site' (54\% ranked as excellent), 'caring and helpfulness of nurses' (53\%), 'response of staff to pain or discomfort' (51\%), 'caring, helpfulness and sensitivity of dialysis staff' $(50 \%)$ and 'ease of reaching staff by telephone' (48\%; figure 1). The five items rated least frequently by respondents as excellent were 'the amount of information when choosing dialysis modality' $(23 \%)$, 'the ease of seeing a social worker when needed' (28\%), 'amount of information from dialysis staff' $(34 \%)$, 'accuracy of information from nephrologist including prognosis and likelihood of getting a kidney transplant' (37\%) and 'accuracy of instructions 
Table 1 Characteristics of participants who responded and those who did not respond to satisfaction survey

\begin{tabular}{|c|c|c|c|}
\hline Characteristic & $\begin{array}{l}\text { Complete or partial response } \\
\text { to survey }(n=2145)\end{array}$ & $\begin{array}{l}\text { No response to } \\
\text { survey }(n=603)\end{array}$ & p Value \\
\hline Age, years & $61.0(15.5)$ & $62.7(14.8)$ & 0.04 \\
\hline Gender, n (\%), male & $1190(55.5)$ & $314(52.1)$ & 0.14 \\
\hline \multicolumn{4}{|l|}{ Highest school education, years } \\
\hline$\leq 5$ & $847(42.1)$ & $238(41.6)$ & \\
\hline$>5$ & $1163(57.9)$ & $334(58.4)$ & 0.82 \\
\hline \multicolumn{4}{|c|}{ Depression score (Center for Epidemiological Studies-Depression Scale) } \\
\hline$<18$ & $947(49.6)$ & $67(46.7)$ & 0.25 \\
\hline$\geq 18$ & $963(50.4)$ & 83 (55.3) & \\
\hline Married & $1303(60.8)$ & $377(62.5)$ & 0.43 \\
\hline Living alone & $275(13.0)$ & 97 (16.2) & 0.04 \\
\hline Distance of housing from dialysis unit, & & & 0.001 \\
\hline$<20$ & $1540(73.1)$ & $392(65.8)$ & \\
\hline$>20$ & 567 (26.9) & 204 (34.2) & \\
\hline Active on waiting list for transplant & $309(14.4)$ & $72(11.9)$ & 0.12 \\
\hline Previous kidney transplant & $148(6.9)$ & $28(4.7)$ & 0.05 \\
\hline Employment & & & 0.002 \\
\hline Employed & $331(15.7)$ & 76 (12.9) & \\
\hline Unemployed & $1451(68.8)$ & $450(76.1)$ & \\
\hline Receiving benefit/pension & $328(15.6)$ & $65(11.0)$ & \\
\hline \multicolumn{4}{|l|}{ Comorbid conditions } \\
\hline Diabetes mellitus & $486(23.5)$ & $146(25.1)$ & 0.42 \\
\hline Hypertension & 1347 (68.5) & 376 (70.3) & 0.65 \\
\hline Prior cardiovascular event & $472(22.0)$ & $124(20.6)$ & 0.45 \\
\hline Time on dialysis, months & $37.3(16.3-70.9)$ & $36.0(17.0-75.7)$ & 0.69 \\
\hline Dialysis treatment time, $\mathrm{min} /$ session & $235.9(20.5)$ & $234.3(23.5)$ & 0.35 \\
\hline Dialysis adequacy, single pool Kt/V & $1.6(0.3)$ & $1.5(0.3)$ & 0.02 \\
\hline Interdialytic weight gain, $\mathrm{kg}$ & $2.29(1.03)$ & 2.37 (1.09) & 0.16 \\
\hline \multicolumn{4}{|l|}{ Serum values } \\
\hline Haemoglobin, $g / L$ & $11.0(1.4)$ & $11.0(1.3)$ & 0.31 \\
\hline Systolic blood pressure, $\mathrm{mm} \mathrm{Hg}$ & $130.0(18.0)$ & $128.4(17.3)$ & 0.07 \\
\hline Serum albumin, $g / L$ & $3.9(0.5)$ & $3.9(0.5)$ & 0.73 \\
\hline Serum phosphorus, $\mathrm{mmol} / \mathrm{L}$ & $4.6(1.4)$ & $4.6(1.4)$ & 0.69 \\
\hline Serum ferritin, $\mu \mathrm{g} / \mathrm{L}$ & $430(242-660)$ & 409 (242-672) & 0.71 \\
\hline Serum parathyroid hormone, $\mathrm{pmol} / \mathrm{L}$ & $282(162-481)$ & $287(167-530)$ & 0.23 \\
\hline Antidepressant medication & $113(5.3)$ & $26(4.3)$ & 0.34 \\
\hline Anxiolytic medication & $291(13.6)$ & $86(14.3)$ & 0.66 \\
\hline Country & & & $<0.0001$ \\
\hline Argentina & 549 (81.9) & $121(18.1)$ & \\
\hline Hungary & $556(81.4)$ & 127 (18.6) & \\
\hline Italy & 648 (73.6) & $232(26.4)$ & \\
\hline Poland & $355(74.4)$ & $122(25.6)$ & \\
\hline Portugal & $37(97.4)$ & $1(2.6)$ & \\
\hline
\end{tabular}

Data are expressed as mean (SD), number (\%), or median (25th centile, 75 th centile). $\mathrm{Kt} / \mathrm{V}$ refers to the clearance of urea and is a measure of the amount of dialysis received.

from nephrologist' $(39 \%)$. In general, the amount of caring and concern shown by staff, particularly by nurses, and the ability of patients to contact dialysis staff were ranked highly, whereas the amount and delivery of information about treatment choices and prognosis as well as access to social worker staff and nephrologists were ranked lowest.

A composite measure of key performance indicators were similar in the included countries during the recruitment period (in descending order with a higher value indicating higher performance: Hungary 1535,
Portugal 1551, Italy 1543, Poland 1381 and Argentina 1303) and were associated with the proportion of respondents reporting excellent overall care (for each unit increase in performance score, the proportion of respondents who ranked care as excellent increased by $0.21 \%$ (95\% CI $-0.02 \%$ to $0.44 \%$ ).

\section{DISCUSSION}

We report the largest study of patient satisfaction with dialysis care to date and identify specific deficits in the 


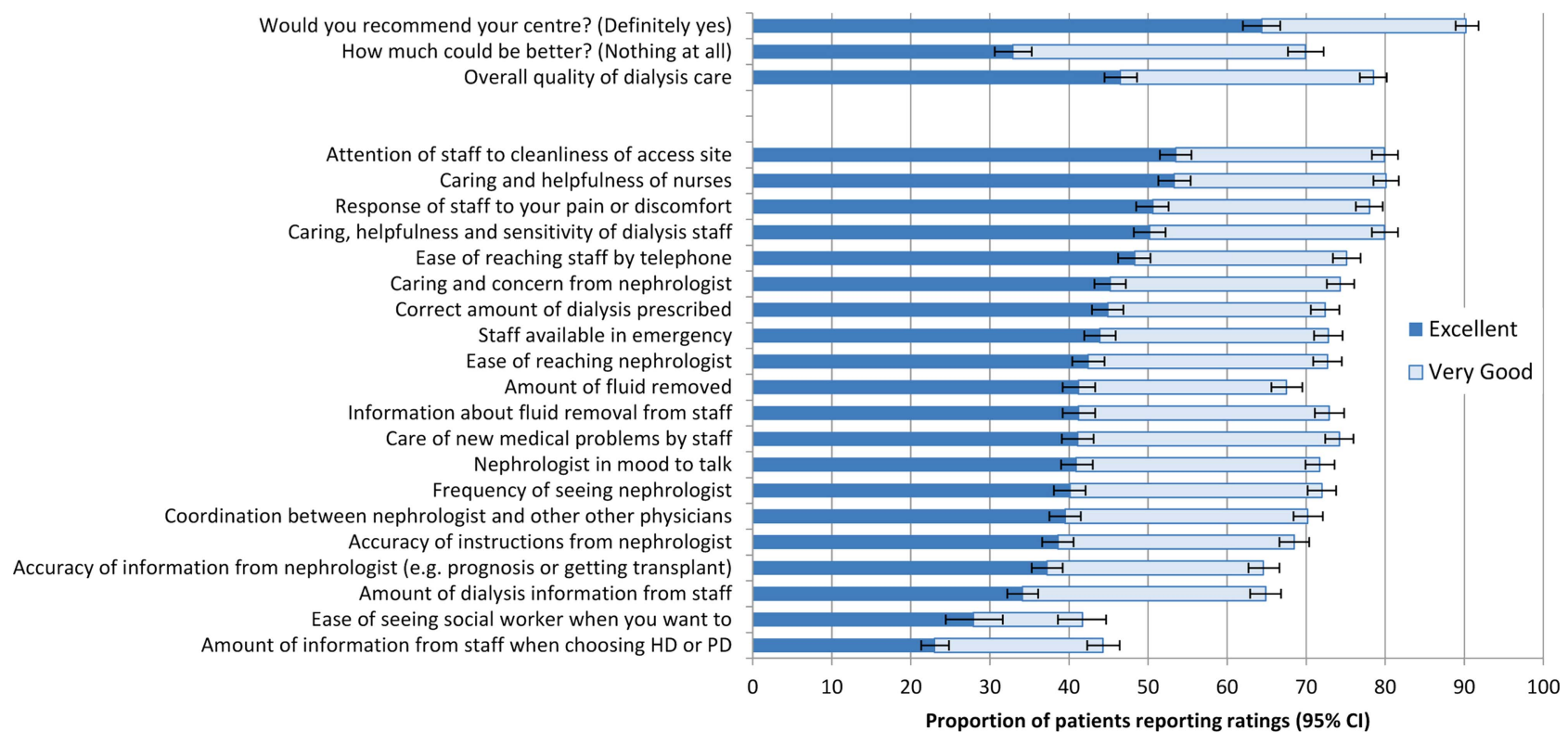

Figure 1 Probabilities of excellent or very good ratings of overall care by dialysis patients.

long-term dialysis care across several countries. Most respondents viewed their overall dialysis care as below excellent and needing improvement. Specifically, while the majority of respondents approved of the more technical aspects of dialysis treatment (attention to the cleanliness of the dialysis vascular access site, caring and helpfulness of nurses and dialysis staff, and attention by staff to immediate needs ( pain, discomfort, sterile procedures)), a minority were satisfied with the more complex and integrated components of care. These were the accuracy and amount of information given by staff to patients about their dialysis treatment, prognosis and making choices between peritoneal dialysis and haemodialysis in addition to support from social worker staff. Older respondents were generally less critical of their haemodialysis care, while those with depressive symptoms were less frequently satisfied. Other demographic and clinical features did not reliably influence perceptions of overall care and the country of treatment had inconsistent effects on satisfaction. Better dialysis care performance scores were associated with higher overall patient satisfaction.

Our patients' perspectives together with other similar studies from the USA ${ }^{19}$ and The Netherlands ${ }^{18}$ emphasise that deficiencies in dialysis care are consistently found and need to be considered specifically when conducting research to improve dialysis patient outcomes. This is particularly relevant as existing interventions in the dialysis setting, including anaemia management, ${ }^{7}$ control of phosphorus ${ }^{29}$ and parathyroid hormone levels, ${ }^{30}$ dialysis dose and flux, ${ }^{9}$ and starting dialysis earlier $^{8}$ have not improved patient well-being despite evaluation in thousands of patients. Our respondents, consistent with the findings of others, ${ }^{31-33}$ report specifically receiving inadequate information about their illness journey and their dialysis treatment options. In our and other chronic diseases settings, patients report needing more information about the causes and progression of their disease, disease symptoms and their impact, and social and financial support. ${ }^{34} 35$ Patients, often due to the competing demands of daily life, rely on healthcare professionals to initiate discussions about care planning and not having future-oriented conversations reduces patients' capacity for hope.$^{36}$ Patients perceive poor communication as reflecting secrecy, misinformation and insensitivity. Subsequently, inadequate information reduces the ability of patients and their families to care for themselves and induces worry. ${ }^{34}$ While education strategies increase patients' willingness to choose self-care dialysis, ${ }^{23}$ the wider effect of educational interventions in the dialysis setting that answer unmet questions about disease trajectory and treatment choices with the aim of improving patient experiences of end-stage kidney disease are not well understood and warrant larger-scale trials. Research in other settings suggest specific interventions to improve information provision, such as training and support for healthcare staff in communication and basic counselling, and overcoming barriers to good communication including addressing time pressures and understaffed environments and considering innovative non-written methods might be appropriate complex strategies for trials in the dialysis setting. ${ }^{34}$

This study indicates that most patients in dialysis settings want more accurate information about their prognosis, in line with experiences of other dialysis patients and those who have cancer. ${ }^{36} 37$ Accurate prognostic information empowers patients ${ }^{38}$; when discussions about prognosis do not occur, patients and their families may (incorrectly) fear the worst. For dialysis patients in our study, the information they receive about prognosis is frequently unsatisfactory including specifically 
Table 2 Proportion of patients who gave an excellent rating to overall haemodialysis care according to patient characteristics

\begin{tabular}{|c|c|c|c|c|}
\hline Characteristic & $\begin{array}{l}\text { Excellent rating } \\
\mathrm{N}(\%)\end{array}$ & $\begin{array}{l}\text { Other rating } \\
\mathrm{N}(\%)\end{array}$ & Unadjusted OR & $\begin{array}{l}\text { Clustering and case } \\
\text { mix adjusted OR }\end{array}$ \\
\hline \multicolumn{5}{|l|}{ Age, years } \\
\hline $18-49$ & $183(19.1)$ & $300(28.1)$ & 1.00 (reference) & 1.00 \\
\hline $50-59$ & $146(15.3)$ & $215(20.1)$ & $1.11(0.84$ to 1.47$)$ & $1.01(0.70$ to 1.44$)$ \\
\hline $59-69$ & $221(23.1)$ & $218(20.4)$ & $1.66(1.28$ to 2.16$)$ & $1.18(0.82$ to 1.69$)$ \\
\hline$\geq 70$ & 406 (42.5) & 335 (31.4) & $1.99(1.57$ to 2.51$)$ & 1.44 (1.01 to 2.04$)$ \\
\hline Male gender & $466(46.1)$ & $483(43.1)$ & $1.13(0.95$ to 1.34$)$ & $1.12(0.88$ to 1.44$)$ \\
\hline \multicolumn{5}{|l|}{ Highest school education, years } \\
\hline$\leq 5$ & $465(49.0)$ & $375(35.8)$ & 1.72 (1.44 to 2.06$)$ & 0.95 (0.74 to 1.21$)$ \\
\hline$>5$ & $485(51.1)$ & 673 (64.2) & 1.00 (reference) & 1.00 \\
\hline \multicolumn{5}{|l|}{ Occupational status } \\
\hline Employed & $120(12.0)$ & $209(19.0)$ & $0.59(0.46$ to 0.75$)$ & 0.79 (0.56 to 1.12$)$ \\
\hline Unemployed or pension & $876(88.0)$ & $893(81.0)$ & 1.00 & 1.00 \\
\hline Married & $601(59.4)$ & $693(61.8)$ & 0.91 (0.76 to 1.08$)$ & $0.86(0.67$ to 1.10$)$ \\
\hline \multicolumn{5}{|c|}{ Distance of housing from dialysis unit, $\mathrm{km}$} \\
\hline$<20$ & 741 (73.9) & $792(72.5)$ & 1.00 & 1.00 \\
\hline$>20$ & $262(26.1)$ & $300(27.5)$ & $0.93(0.77$ to 1.13 & $1.18(0.91$ to 1.54$)$ \\
\hline Waiting list for kidney transplant & $131(13.0)$ & $176(15.7)$ & 0.80 (0.63 to 1.02$)$ & 0.80 (0.56 to 1.14$)$ \\
\hline \multicolumn{5}{|l|}{ Comorbid conditions } \\
\hline Diabetes mellitus & $249(25.4)$ & $233(21.6)$ & 1.24 (1.01 to 1.52$)$ & 1.38 (0.78 to 2.46$)$ \\
\hline Prior cardiovascular event & $248(24.5)$ & $220(19.6)$ & 1.33 (1.08 to 1.63$)$ & 0.89 (0.63 to 1.26$)$ \\
\hline \multicolumn{5}{|c|}{ Center for Epidemiological Studies-Depression Scale score } \\
\hline$<18$ & $472(52.5)$ & $472(47.2)$ & 1.00 (reference) & 1.00 (reference) \\
\hline$\geq 18$ & 427 (47.5) & $527(52.8)$ & 0.81 (0.68 to 0.97$)$ & $0.56(0.44$ to 0.71$)$ \\
\hline \multicolumn{5}{|l|}{ Dialysis adequacy, single pool Kt/V } \\
\hline$<1.4$ & $202(20.6)$ & $245(22.2)$ & 1.00 (reference) & 1.00 \\
\hline$\geq 1.4$ & 778 (79.4) & $856(77.8)$ & $1.10(0.89$ to 1.36$)$ & $1.11(0.83$ to 1.49$)$ \\
\hline \multicolumn{5}{|l|}{ Serum phosphorus, $\mathrm{mmol} / \mathrm{L}$} \\
\hline$<1.45$ & $516(51.5)$ & 509 (45.9) & 1.00 (reference) & 1.00 \\
\hline$\geq 1.45$ & $486(48.5)$ & $601(54.1)$ & $0.80(0.67$ to 0.95$)$ & 0.96 (0.76 to 1.23$)$ \\
\hline \multicolumn{5}{|l|}{ Haemoglobin, g/L } \\
\hline$<110$ & 476 (47.6) & $537(48.2)$ & 1.00 (reference) & 1.00 \\
\hline$\geq 110$ & $525(52.4)$ & $578(51.8)$ & $1.02(0.86$ to 1.22$)$ & 0.90 (0.71 to 1.14$)$ \\
\hline \multicolumn{5}{|l|}{ Albumin, $\mathrm{g} / \mathrm{dL}$} \\
\hline$<3.8$ & $371(37.8)$ & $369(33.7)$ & 1.00 (reference) & 1.00 \\
\hline $3.8-4.0$ & 277 (28.2) & $324(29.6)$ & 0.85 (0.69 to 1.05$)$ & $1.07(0.80$ to 1.42$)$ \\
\hline$\geq 4.1$ & 333 (33.9) & $401(36.6)$ & $0.83(0.67$ to 1.01 & 0.78 (0.58 to 1.05$)$ \\
\hline \multicolumn{5}{|l|}{ Systolic blood pressure, $\mathrm{mm} \mathrm{Hg}$} \\
\hline$\leq 120$ & $270(27.2)$ & $353(32.1)$ & 1.00 (reference) & 1.00 \\
\hline $121-140$ & $404(40.6)$ & $441(40.0)$ & $1.20(0.97$ to 1.47$)$ & 0.89 (0.67 to 1.19$)$ \\
\hline$\geq 140$ & $320(32.2)$ & 307 (27.9) & 1.36 (1.09 to 1.70$)$ & $1.03(0.76$ to 1.40$)$ \\
\hline \multicolumn{5}{|l|}{ Country } \\
\hline Poland & $48(4.8)$ & $303(27.0)$ & 0.09 (0.07 to 0.13$)$ & - \\
\hline Argentina & $172(17.0)$ & 372 (33.2) & $0.28(0.22$ to 0.35$)$ & - \\
\hline Italy & $405(40.1)$ & $242(21.6)$ & 1.00 (reference) & - \\
\hline Hungary & $355(35.1)$ & $198(17.7)$ & $1.07(0.85$ to 1.36$)$ & - \\
\hline Portugal & $31(3.1)$ & $6(0.5)$ & 3.09 (1.27 to 7.51$)$ & - \\
\hline
\end{tabular}

Clustering and case mix adjusted model controlled for age, gender, education level, occupational status, marital status, distance from dialysis centre, activity on transplant waiting list, comorbid conditions (diabetes, hypertension, cardiovascular event) depression score, cause of end-stage kidney disease, duration of dialysis per session and dialysis dose, dialysis adequacy (Kt/V), serum values (haemoglobin, phosphorus) and country.

understanding their chances of receiving a kidney transplant and their survival. Physicians in other medical specialties similarly provide insufficient information about $\operatorname{prognosis}^{39}$ and infrequently check their patients' understanding during consultations. ${ }^{40}$ Physicians commonly find disclosing prognosis stressful and desire more training and guidance for this aspect of clinical practice. ${ }^{41}$ Our findings suggest that meeting patients' expectations about information is an important but potentially neglected aspect of dialysis care and is consistent with the data showing that patients are infrequently involved in discussions about prognosis and 
likelihood of transplantation. ${ }^{33}$ The effect of increased clinician training in prognosis provision about survival and transplantation could form the basis of a testable strategy in future health services research in dialysis.

The patient-centred movement in healthcare ('nothing about me without me') ${ }^{42}$ has engendered considerable data on the issues of most importance to patients and their families to highlight the mismatch between patients' values and the outcomes routinely measured in research and clinical practice, including for patients with advanced kidney disease. ${ }^{5}{ }^{43}$ While landmark trials in nephrology over the past three decades have measured treatment effectiveness using biomarker levels and major cardiovascular events and survival, emerging data show that patients are frequently willing to forgo survival in exchange for fewer restrictions on their daily life, and prioritise collaborative research aimed at improving the way they feel, function and survive. ${ }^{5}{ }^{6}$ In addition, contemporary studies of communication and educational strategies as well as complex healthcare service changes in dialysis have used similarly quantitative outcomes to assess treatment effectiveness, which have included urgent dialysis start, vascular access processes and survival. ${ }^{20} 2144$ We suggest that, in line with patient-centred data, trials of communication or education for dialysis patients might consider aspects of quality of life valued by patients as key outcomes for assessing effectiveness.

Notably, patient satisfaction was largely unrelated to most clinical or demographic patient characteristics despite a large sample size and similar to other studies in the US A and The Netherlands, suggesting that lower satisfaction of many aspects of dialysis care is a global patient experience. Older patients in this study rated their overall care more highly, consistent with a recent study of patient perceptions of dialysis care in The Netherlands, ${ }^{18}$ and of studies of patient satisfaction across health services more generally, ${ }^{45} 46$ despite the evidence that older patients may actually receive lower quality care. ${ }^{47}$ In contrast, depressive symptoms markedly reduced satisfaction in this study (even when controlling for markers of health status and comorbidity); similar findings have been reported in other settings. ${ }^{48}$ Those with depressive symptoms voluntarily ration the time they have with medical staff, which may in turn impair patient-clinician communication and serve to decrease their satisfaction with care overall. ${ }^{48}$ Notably, in other chronic disease settings, patient satisfaction is increased in association with better patient-clinician interaction and support for patient self-management, ${ }^{49}$ and high levels of patient satisfaction for interpersonal skills, technical quality and access to care can be present in chronic illness settings such as diabetes mellitus and rheumatoid arthritis. ${ }^{50}$

\section{Limitations of the study}

Although we provide considerable satisfaction data for dialysis patients in several countries, our analysis should be interpreted in light of the study limitations. First, we did not evaluate in detail the influence of healthcare systems in which the dialysis clinics were situated (including features such as staffing-levels ${ }^{51}$ or number of beds ${ }^{52}$ ) on patient satisfaction, although we did find an association between overall satisfaction and global clinical performance. While interpersonal relations with healthcare workers are the most frequently mentioned by patients when asked to rate their care, contextual factors relating to conditions of medical services are also described commonly by patients and often lead to negative comments about healthcare. ${ }^{53}$ Second, we took a quantitative approach to assessing patients' perceptions, which may be suboptimal for understanding the full range of feelings, values and experiences of receiving dialysis care. In addition, satisfaction and dissatisfaction may not simply be alternative ends of a single spectrum of perception and may in fact exist side-by-side within a patient's experience of care. ${ }^{54}$ Third, we did not capture satisfaction with a specific healthcare event and surveyed patients who had been treated with dialysis for 3 years on average. The potential lag between pivotal patient experiences and the survey may have introduced recall bias. ${ }^{55}$ Fourth, we did not capture longitudinal data to determine any association between perceptions of care and health-related behaviour and outcomes including healthcare utilisation, quality of life or survival. Finally, the findings in this study may not be applicable to other dialysis settings including peritoneal dialysis or home-based haemodialysis care and regional settings outside our survey countries including many USA, European and UK dialysis settings. In addition, the study survey predates more widespread use of haemodiafiltration which may be associated with greater haemodynamic stability during dialysis therapy and different levels of patient satisfaction.

\section{Implications of the study}

As measures of patient experience are distinctive indicators of healthcare quality, ${ }^{55}$ our analysis suggests that several strategies might improve care for patients in the later stages of chronic kidney disease. First, patients need better information about their choices of treatment for end-stage kidney disease including dialysis modalities. A recent systematic review suggests that this is optimally provided when the glomerular filtration rate falls below $30 \mathrm{~mL} / \mathrm{min} / 1.73 \mathrm{~m}^{2}$ and well in advance of preparations for dialysis vascular access. ${ }^{31}$ Second, formal care strategies that provide patients with information about prognosis and the impact of end-stage kidney disease and its treatments on their life earlier in the course of kidney disease need to be developed and assessed. Current practices for assessing and discussing prognosis are manifestly inadequate,${ }^{36}$ and our present reliance on individual physicians to initiate such discussions is not meeting the needs of our patients. Third, better delivery of information about dialysis from nephrologists and dialysis staff is expected by patients, and greater understanding of the 
information that patients need and optimal mode(s) of delivery may improve care.

\section{CONCLUSION}

This large study of patient satisfaction with different aspects of long-term haemodialysis care suggests that patients' needs are not being fully met. The findings suggest that meeting patient expectations about information on dialysis choices and prognosis may be critical for improving patient experiences of long-term dialysis care and can form the basis for future healthcare services research in the dialysis setting.

\author{
Author affiliations \\ ${ }^{1}$ Department of Medicine, University of Otago Christchurch, Christchurch, New \\ Zealand \\ ${ }^{2}$ Consorzio Mario Negri Sud, S. Maria Imbaro, Italy \\ ${ }^{3}$ School of Public Health, University of Sydney, Sydney, New South Wales, \\ Australia \\ ${ }^{4}$ Division of Nephrology and Immunology, University of Alberta, Edmonton, \\ Canada \\ ${ }^{5}$ Scientific Institute Casa Sollievo della Sofferenza, Italy \\ ${ }^{6}$ Diaverum Scientific Medical Office, Lund, Sweden \\ ${ }^{7}$ Department of Emergency and Organ Transplantation, University of Bari, \\ Bari, Italy \\ ${ }^{8}$ Division of Nephrology and Transplantation, Department of Translational \\ Medicine,Amedeo Avogadro University of Eastern Piedmont, Novara, Italy
}

Acknowledgements The authors would wish to acknowledge the contribution of all patients who responded to surveys included in this analysis.

Contributors SCP designed the study, interpreted data analysis, wrote the first draft and revised the paper. GdB designed the data analysis, cleaned and analysed data, and drafted and revised the paper. JCC assisted with study design, interpreted the data analysis, and drafted and revised the paper. AT interpreted the data analysis, and drafted and revised the paper. MT assisted with data collection tools, interpreted the data analysis and drafted and revised the paper. FP interpreted the data analysis and revised the paper. MR monitored data collection for the whole study, assisted with data collection and cleaning, interpreted the data analysis and revised the paper. $\mathrm{JH}$ and CW interpreted the data analysis and revised the paper. EC, RG, JNF, $\mathrm{MT}, \mathrm{ML}, \mathrm{AB}-\mathrm{S}$ and JD assisted with data collection, interpreted the data analysis and revised the paper. GFMS designed the study and data collection tools, monitored data collection for the whole study, interpreted the data analysis and drafted and revised the paper. He is the guarantor. All authors had full access to all of the data (including statistical reports and tables) in the study and can take responsibility for the integrity of the data and the accuracy of the data analysis.

Funding This study was funded by an unrestricted educational grant from Diaverum.

Competing interests GFMS is Senior Vice-President of Scientific Affairs at Diaverum. JH is Senior Vice-President Medical Operations-Chief Medical Officer of Diaverum. MR, CW, EC, RG, JNF, MT, ML, AB-S and JD are employees of Diaverum. SCP receives a fellowship from the Consorzio Mario Negri Sud, Italy provided by an unrestricted educational grant from Amgen Dompé. SCP is a 2012 L'Oreal UNESCO For Women in Science Australia and New Zealand Fellow.

Ethics approval We obtained ethics approval for the analyses of routinely collected data from the University of Sydney Human Research Ethics Committee on 27 February 2013. The authorised personnel are AT, JCC and GFMS. The project number for approval was 2013/031 and included approval of the satisfaction survey, the data custodian (Diaverum) and the survey data dated January 2008.
Provenance and peer review Not commissioned; externally peer reviewed.

Data sharing statement No additional data are available.

Open Access This is an Open Access article distributed in accordance with the Creative Commons Attribution Non Commercial (CC BY-NC 3.0) license, which permits others to distribute, remix, adapt, build upon this work noncommercially, and license their derivative works on different terms, provided the original work is properly cited and the use is non-commercial. See: http:// creativecommons.org/licenses/by-nc/3.0/

\section{REFERENCES}

1. US Renal Data System. USRDS 2012 annual data report: Atlas of chronic kidney disease and end-stage renal disease in the United States. Bethesda, MD: National Institutes of Health, National Institute of Diabetes and Digestive and Kidney Diseases, 2012.

2. Evans RW, Manninen DL, Garrison LP Jr, et al. The quality of life of patients with end-stage renal disease. $N$ Engl J Med 1985;312:553-9.

3. Wyld M, Morton RL, Hayen A, et al. A systematic review and meta-analysis of utility-based quality of life in chronic kidney disease treatments. PLOS Med 2012;9:e1001307.

4. Murtagh FE, Addington-Hall J, Higginson IJ. The prevalence of symptoms in end-stage renal disease: a systematic review. Adv Chronic Kidney Dis 2007;14:82-99.

5. Tong A, Sainsbury P, Carter SM, et al. Patients' priorities for health research: focus group study of patients with chronic kidney disease. Nephrol Dial Transplant 2008;23:3206-14.

6. Morton RL, Snelling P, Webster AC, et al. Dialysis modality preference of patients with CKD and family caregivers: a discrete-choice study. Am J Kidney Dis 2012;60:102-11.

7. Phrommintikul A, Haas SJ, Elsik M, et al. Mortality and target haemoglobin concentrations in anaemic patients with chronic kidney disease treated with erythropoietin: a meta-analysis. Lancet 2007;369:381-8.

8. Cooper BA, Branley P, Bulfone L, et al. A randomized, controlled trial of early versus late initiation of dialysis. $N$ Engl $J$ Med 2010;363:609-19.

9. Eknoyan G, Beck GJ, Cheung AK, et al. Effect of dialysis dose and membrane flux in maintenance hemodialysis. N Engl J Med 2002;347:2010-19.

10. EVOLVE Trial Investigators, Chertow GM, Block GA, Effect of cinacalcet on cardiovascular disease in patients undergoing dialysis. N Engl J Med 2012;367:2482-94.

11. Besarab A, Bolton WK, Browne JK, et al. The effects of normal as compared with low hematocrit values in patients with cardiac disease who are receiving hemodialysis and epoetin. $N$ Engl J Med 1998;339:584-90.

12. Nissenson AR. Improving outcomes for ESRD patients: shifting the quality paradigm. Clin J Am Soc Nephrol 2014;9:430-4.

13. Jansen DL, Heijmans MJ, Rijken M, et al. Illness perceptions and treatment perceptions of patients with chronic kidney disease: different phases, different perceptions? Br J Health Psychol 2013;18:244-62.

14. Federal Register Centers for Medicare and Medicad Services 42 CFR Parts 413 and 414. Medicare Program; End-Stage renal Disease Prospective Payment System and Quality Incentive Program; Ambulance fee Schedule; Durable Medical Equipment; and Competitive Acquisition of Certain Durable Medical Equipment, Prosthetics, Orthotics, and Supplies. http://www.gpo.gov/fdsys/pkg/ FR-2011-11-10/pdf/2011-28606.pdf (accessed 23 Nov 2012).

15. Lacson $\mathrm{E} \mathrm{Jr}$, Wang W, Lazarus JM, et al. Hemodialysis facility-based quality-of-care indicators and facility-specific patient outcomes. Am J Kidney Dis 2009;54:490-7.

16. Plantinga LC, Fink NE, Jaar BG, et al. Attainment of clinical performance targets and improvement in clinical outcomes and resource use in hemodialysis care: a prospective cohort study. BMC Health Serv Res 2007;7:5.

17. Vanholder R, Davenport A, Hannedouche T, et al. Reimbursement of dialysis: a comparison of seven countries. J Am Soc Nephrol 2012;23:1291-8.

18. van der Veer SN, Arah OA, Visserman E, et al. Exploring the relationships between patient characteristics and their dialysis care experience. Nephrol Dial Transplant 2012;27:4188-96.

19. Rubin HR, Fink NE, Plantinga LC, et al. Patient ratings of dialysis care with peritoneal dialysis vs hemodialysis. JAMA 2004;291:697-703. 
20. Devins GM, Mendelssohn DC, Barre PE, et al. Predialysis psychoeducational intervention extends survival in CKD: a 20-year follow-up. Am J Kidney Dis 2005;46:1088-98.

21. Jungers $P$, Massy ZA, Nguyen-Khoa $T$, et al. Longer duration of predialysis nephrological care is associated with improved long-term survival of dialysis patients. Nephrol Dial Transplant 2001;16:2357-64.

22. Winkelmayer WC, Owen WF Jr, Levin R, et al. A propensity analysis of late versus early nephrologist referral and mortality on dialysis. J Am Soc Nephrol 2003;14:486-92.

23. Manns BJ, Taub K, Vanderstraeten C, et al. The impact of education on chronic kidney disease patients' plans to initiate dialysis with self-care dialysis: a randomized trial. Kidney Int 2005;68: 1777-83.

24. Bayliss E, Bhardwaja B, Ross C, et al. Multidisciplinary team care may slow the rate of decline in renal function. Clin J Am Soc Nephrol 2011;6:704-10.

25. ERA-EDTA Registry. ERA-EDTA registry annual report 2010. Amsterdam, The Netherlands: Academic Medical Center, Department of Medical Informatics. http://www.era-edta-reg.org/files/ annualreports/pdf/AnnRep2010.pdf (accessed 4 Mar 2014).

26. Rubin HR, Jenckes M, Fink NE, et al. Patient's view of dialysis care: development of a taxonomy and rating of importance of different aspects of care. CHOICE study. Choices for Healthy Outcomes in Caring for ESRD. Am J Kidney Dis 1997;30:793-801.

27. Snijders TAB, Bosker R. Multilevel analysis: an introduction to basic and advanced multilevel modeling. London: Sage, 1999.

28. Sullivan LM, Dukes KA, Losina E. Tutorial in biostatistics. An introduction to hierarchical linear modelling. Stat Med 1999;18:855-88.

29. Suki WN, Zabaneh R, Cangiano JL, et al. Effects of sevelamer and calcium-based phosphate binders on mortality in hemodialysis patients. Kidney Int 2007;72:1130-7.

30. Palmer SC, Nistor I, Craig JC, et al. Cinacalcet in patients with chronic kidney disease: a cumulative meta-analysis of randomized controlled trials. PLoS Med 2013;10:e1001436.

31. Morton RL, Tong A, Howard K, et al. The views of patients and carers in treatment decision making for chronic kidney disease: systematic review and thematic synthesis of qualitative studies. BMJ 2010;340:c112.

32. Ormandy P. Information topics important to chronic kidney disease patients: a systematic review. J Ren Care 2008;34:19-27.

33. Wachterman M, Marcantonio E, Davis R, et al. Relationship between the prognostic expectations of seriously ill patients undergoing hemodialysis and their nephrologists. JAMA Intern Med 2013;173:1206-14.

34. Selman L, Higginson IJ, Agupio G, et al. Meeting information needs of patients with incurable progressive disease and their families in South Africa and Uganda: multicentre qualitative study. BMJ 2009;338:b1326

35. Francis V, Korsch BM, Morris MJ. Gaps in doctor-patient communication. N Engl J Med 1969;280:535-40.
36. Davison SN, Simpson C. Hope and advance care planning in patients with end stage renal disease: qualitative interview study. BMJ 2006;333:886

37. Hagerty RG, Butow PN, Ellis PM, et al. Communicating prognosis in cancer care: a systematic review of the literature. Ann Oncol 2005;16:1005-53

38. Mack JW, Wolfe J, Cook EF, et al. Hope and prognostic disclosure. $J$ Clin Oncol 2007;25:5636-42.

39. Audrey S, Abel J, Blazeby JM, et al. What oncologists tell patients about survival benefits of palliative chemotherapy and implications for informed consent: qualitative study. BMJ 2008;337:a752.

40. Gattellari M, Voigt KJ, Butow PN, et al. When the treatment goal is not cure: are cancer patients equipped to make informed decisions? $J$ Clin Oncol 2002;20:503-13.

41. Fallowfield L, Jenkins V. Communicating sad, bad, and difficult news in medicine. Lancet 2004;363:312-19.

42. Barry MJ, Edgman-Levitan S. Shared decision making-the pinnacle of patient-centered care. N Engl J Med 2012;366:780-1.

43. Howell M, Tong A, Wong G, et al. Important outcomes for kidney transplant recipients: a nominal group and qualitative study. $A m \mathrm{~J}$ Kidney Dis 2012;60:186-96.

44. Levin A, Lewis M, Mortiboy $P$, et al. Multidisciplinary predialysis programs: quantification and limitations of their impact on patient outcomes in two Canadian settings. Am J Kidney Dis 1997;29:533-40.

45. Bowling A. An 'inverse satisfaction law'? Why don't older patients criticise health services? J Epidemiol Community Health 2002;56:482.

46. Jaipaul CK, Rosenthal GE. Are older patients more satisfied with hospital care than younger patients? J Gen Intern Med 2003;18:23-30.

47. Meehan T, Fine MJ, Krumholz HM, et al. Quality of care, process, and outcomes in elderly patients with pneumonia. JAMA 1997;278:2080-4

48. Schenker $\mathrm{Y}$, Stewart $\mathrm{A}, \mathrm{Na} \mathrm{B}$, et al. Depressive symptoms and perceived doctor-patient communication in the Heart and Soul study. J Gen Intern Med 2009;24:550-6.

49. Carlin CS, Christianson JB, Keenan P, et al. Chronic illness and patient satisfaction. Health Serv Res 2012;47:2250-72.

50. Bidaut-Russell M, Gabriel SE, Scott CG, et al. Determinants of patient satisfaction in chronic illness. Arthritis Rheum 2002;47:494-500

51. Needleman J, Buerhaus $P$, Mattke $S$, et al. Nurse-staffing levels and the quality of care in hospitals. N Engl J Med 2002;346:1715-22.

52. Jha AK, Orav EJ, Zheng J, et al. Patients' perception of hospital care in the United States. N Engl J Med 2008;359:1921-31.

53. Marcinowicz L, Chlabicz S, Grebowski R. Patient satisfaction with healthcare provided by family doctors: primary dimensions and an attempt at typology. BMC Health Serv Res 2009;9:63.

54. Coyle J. Exploring the meaning of 'dissatisfaction' with health care: the importance of 'personal identity threat'. Sociol Health IIIn 1999;21:95-124.

55. Manary MP, Boulding $\mathrm{W}$, Staelin R, et al. The patient experience and health outcomes. N Engl J Med 2013;368:201-3. 